\title{
Article \\ Short-Run Links in Ecological Footprint: A Dynamic Factor Analysis for the EU
}

\author{
María Jesús Delgado-Rodríguez ${ }^{1, *(1)}$, Sonia de Lucas-Santos ${ }^{2}\left(\mathbb{D}\right.$ and Alfredo Cabezas-Ares ${ }^{1}$ (D) \\ 1 Department of Business Administration (ADO), Applied Economics II and Fundaments of Economic Analysis, \\ Universidad Rey Juan Carlos de Madrid, $\mathrm{P}^{\circ}$ Artilleros s/n, 28670 Madrid, Spain; alfredo.cabezas@urjc.es \\ 2 Department of Applied Economics (Statistics), Ciudad Universitaria de Cantoblanco, \\ Universidad Autónoma de Madrid, 28049 Madrid, Spain; sonia.delucas@uam.es \\ * Correspondence: mariajesus.delgado@urjc.es; Tel.: +34-91-488-7852
}

check for updates

Citation: Delgado-Rodríguez, M.J.; Lucas-Santos, S.d.; Cabezas-Ares, A. Short-Run Links in Ecological Footprint: A Dynamic Factor Analysis for the EU. Land 2021, 10, 1372. https://doi.org/10.3390/ land10121372

Academic Editor: Benedetto Rugani

Received: 16 November 2021

Accepted: 9 December 2021

Published: 11 December 2021

Publisher's Note: MDPI stays neutral with regard to jurisdictional claims in published maps and institutional affiliations.

Copyright: (c) 2021 by the authors. Licensee MDPI, Basel, Switzerland. This article is an open access article distributed under the terms and conditions of the Creative Commons Attribution (CC BY) license (https:// creativecommons.org/licenses/by/ $4.0 /)$.

\begin{abstract}
The Ecological Footprint (EFP) is a useful indicator for assessing the progress of environmental performance and offers a solid basis for sustainability studies. In this paper, we contribute to the broadening of its possibilities of investigation by measuring the cross-country links in the EFP in global hectares per capita. The modeling framework is based on the dynamic factor analysis to estimate, in the parametric form, an index that provides information about the short-run dynamics of the EFP in the EU. Following this approach, we identify different patterns in the EFP behavior of the European countries during the period of 1962-2017. The results show stronger links across the EFP of the main European countries: France, Austria, Belgium, Germany, Denmark and the U.K. The proposed analysis gives a better understanding of the links behind environmental degradation in the EU and is applicable for the implementation and design of environmental policies.
\end{abstract}

Keywords: ecological footprint; dynamic factor model; cross-country links

\section{Introduction}

As a world leader in taking action on climate change, the EU has constantly demanded environmental regulations to combat it. Currently, Europe faces unprecedented environmental, climate and sustainability challenges. These include biodiversity loss, climate change, resource use and pollution, which require strong commitments to respond to them. For this purpose, the European Commission published a proposal for an 8th Environment Action Programme in 2020 in order to ensure that the EU climate and environment laws are effectively implemented. It forms the EU's basis for achieving the United Nations' 2030 Agenda and its Sustainable Development Goals. This proposal also supports the environment and climate action objectives of the European Green Deal.

The monitoring and assessment of these plans require the development of innovative and comprehensive indicators that are capable of providing information of interest for the implementation of policies related to global warming and climate change. Environmental variables are important as proxies to represent degradation and to track the efforts in the struggle against environmental threats. Traditionally, the variables of carbon emission and pollution type (degradation in land, forest, water, etc.) have been widely used in the literature to constitute policy rules. Recently, the ecological-footprint indicator has attracted attention in research and is highlighted as one of the most prominent environmental-variable and sustainability-evaluation tools. The EFP is an aggregate indicator that measures the environmental degradation caused by human activities (Ulucak and Lin, 2017 [1]). It helps individuals to understand the direct and indirect impact of their actions on the planet. According to the Global Footprint Network (2021) [2], on the demand side, the EFP represents the ecological assets that a population requires in order to produce all of the resources they consume, including livestock-based food, fishery products, forestry, and infrastructure. This variable is calculated in global hectares. The EFP is categorized by 
land type, and there are six types of ecological footprints: arable-land EFP, forest-land EFP, grazing-land EFP, fishing-land EFP, built-up-land EFP and carbon-uptaking-land EFP.

Much of the empirical analysis of EFPs has been dedicated to determining convergence in countries in order to provide administrators and societies with policy recommendations. It is expected that the countries that converge in environmental indicators will be able to implement their policies more effectively in the context of a common environmental framework. Therefore, the issue of whether or not countries converge has received great attention in the literature. The empirical findings of the EFP document the presence of a number of convergence clubs (Ulucak and Aperguis, 2018 [3]) and the existence of a convergence in income in groups of countries (Erdogan and Okumus, 2021 [4]). Thus, convergence is verified for countries with similar conditions, such as the growth process or the dependence on environmental resources. The existence of club convergence or groups of countries that converge suggests that environmental policies should consider the different convergence paths associated with them. Furthermore, these results demonstrate that certain countries have similar dynamics and conditions in regards to the drivers of environmental quality and environmental degradation.

Despite its undoubted interest, these works have focused only on the long-run side of the analysis, while the short-term analysis of the EFP has been ignored. The short-run approach can be of interest to supplementing and improving research into the efficiency of environmental policies. This makes it very interesting to delve into the short-term characteristics and dynamics of the EFP in the EU and the possible links between countries. In this paper, we estimate a Dynamic Factor Model in order to assess information about how the EFP co-moves across European countries. In our analysis, the fact that countries share the same short-run dynamics in the EFP indicates linkages across them that can be of interest to the design of the EU climate change policy.

This paper is motivated by these concerns and extends the research into the EFP by investigating the possibility of cross-country links of 21 European countries for the 1961-2017 period. We contribute to the existing literature on the EFP in two distinct ways. Firstly, we introduce the short-run perspective in the study of the EFP by estimating the short-run index of the EFP in the EU based on the dynamic factor model. Secondly, we assess the links across countries by measuring the degree to which European countries share the dynamic pattern of the EFP in Europe. In this paper, we offer an innovative empirical approach that may be a useful tool to evaluate the features of EFP performance across member states. The results could lead to environmental recommendations on which countries should make further adjustments in order to increase efforts to reduce EFP.

We arrange the remainder of this paper as follows: the next section presents the literature review on the recent papers on EFP analysis. The third section describes the data and the econometric strategy. The empirical results are reported in the fourth section. The final section presents the conclusion and the policy recommendations.

\section{Literature}

The most recent sustainability analyses have focused on the use of EFP indicators for the assessment of progress on environmental performance. The concept of the EFP is considered a more comprehensive indicator than other environmental measures (Al-Mulali et al., 2015, Solarin, $2019[5,6])$. Traditionally, papers on sustainability analysis have mostly used information about $\mathrm{CO}_{2}$ emissions. However, $\mathrm{CO}_{2}$ emissions only represent a fraction of the total fallout triggered by large-scale energy use (Al-Mulali et al., 2015, Solarin, 2019 [5,6]). Beyond $\mathrm{CO}_{2}$ emissions, resource stocks including forestry soil, mining and oil stock also put nature under immense pressure. According to Stern (2014) [7], the developed countries have experienced a decline in many specific pollutants per unit of output due to technological innovations and progressively stringent environmental regulations. For this reason, the use of indicators that provide information on environmental degradation in terms of the EFP is increasingly in demand (Bello et al. 2018 [8]; Solarin and Al-Mulali 2018 [9]). 
Some novel and recent studies focusing on the use of the EFP in environmental analyses are shown in Table 1, which briefly summarizes them. The relevant literature review demonstrates that the analysis of the EFP is a promising area of research. However, most of these studies have focused on convergence analysis. These papers have especially evaluated the long-term dynamics of per capita emissions and tried to determine whether the national data series show evidence of converging trends in the sense that nations that initially have lower levels of EFP per capita are encountering a higher growth in emissions and are therefore "catching up" with the nations that have a higher EFP per capita. Solarin (2019) [6] showed evidence of sigma convergence in the EFP for 27 OECD countries. Bilgili and Uluak (2018) [10] offered evidence in favor of environmental convergence by demonstrating the stochastic and deterministic convergences among the G20 countries. Yilanci and Pata (2020) [11] investigated the convergence process for the ASEAN-5 countries and provided strong support for the absolute convergence in the EFP per capita. Sarkodie (2021) [12] also confirmed long-run convergence for 242 countries using cross-country time series techniques.

Table 1. Recent empirical sustainability analysis based on environmental degradation variables.

\begin{tabular}{|c|c|c|c|c|}
\hline Study & Variable & Methodology & Sample & Results \\
\hline Solarin 2019 [6] & $\begin{array}{c}\mathrm{CO}_{2} \text { emissions, } \\
\text { Carbon Footprint pc } \\
\text { and EFP pc }\end{array}$ & Stochastic convergence & 27 OCDE Countries & Sigma convergence \\
\hline Bilgili \& Ulucak 2018 [10] & EFP & $\begin{array}{l}\text { A bootstrap-based } \\
\text { panel KPSS test }\end{array}$ & G-20 Countries & $\begin{array}{l}\text { Stochastic and } \\
\text { deterministic C. }\end{array}$ \\
\hline Ulucak \&Apergis 2018 [3] & EFP & $\begin{array}{l}\text { Club-clustering } \\
\text { approach }\end{array}$ & EU Countries & Convergence clubs \\
\hline Solarin et al., 2019 [13] & $\begin{array}{c}\text { EFP and its } \\
\text { six components }\end{array}$ & $\begin{array}{l}\text { Club-convergence } \\
\text { approach }\end{array}$ & 92 countries & Convergence clubs \\
\hline Yilanci \& Pata 2020 [11] & EFP & TAR panel unit root test & 5 ASEAN countries & Absolute convergence \\
\hline Ulucak et al., 2020 [14] & $\begin{array}{c}\text { EFP and its } \\
\text { sub-components }\end{array}$ & Log $t$ regression & $\begin{array}{l}33 \text { Sub-Saharan } \\
\text { countries }\end{array}$ & Convergence clubs \\
\hline Erdogan \& Okumus 2020 [4] & EFP & $\begin{array}{l}\text { Stochastic and club } \\
\text { convergence approach }\end{array}$ & 89 countries & Convergence clubs \\
\hline Haider et al., 2021 [15] & $\begin{array}{l}\text { Biomass material } \\
\text { Footprint }\end{array}$ & Phillips-Sul approach & 172 Countries & No convergence \\
\hline Sarkodie 2021 [12] & $\begin{array}{l}\text { EFP, Biocapacity, } \\
\text { Carbon F., and } \\
\text { Ecological Status }\end{array}$ & $\begin{array}{l}\text { Cross-country time } \\
\text { series techniques }\end{array}$ & 245 Countries & Long-run convergence \\
\hline Wu 2020 [20] & EFP & GWR and OLS models & Provinces of China & $\begin{array}{l}\text { Main driving forces of } \\
\text { EFP evolution }\end{array}$ \\
\hline Wu \& Liu 2020 [17] & EFP Intensity & $\begin{array}{l}\text { Global Moran's Index } \\
\text { and LISA }\end{array}$ & Jiangsu's counties & Spatial distribution \\
\hline Nathaniel et al., 2020 [19] & EFP & $\begin{array}{l}\text { AMG estimation and } \\
\text { panel co-integration }\end{array}$ & CIVETS countries & $\begin{array}{c}\text { Relation economic } \\
\text { variables }\end{array}$ \\
\hline Guo et al., 2020 [21] & $\begin{array}{c}\text { EFP and Ecological } \\
\text { Capacity }\end{array}$ & $\begin{array}{c}\text { Grey GM }(1,1) \\
\text { prediction model }\end{array}$ & $\begin{array}{l}\text { Quinghai Province } \\
\text { (China) }\end{array}$ & Forecasting EFP \\
\hline Caglar et al., 2021 [16] & $\begin{array}{c}\text { EFP and its } \\
\text { six components }\end{array}$ & SOR unit root test & $\begin{array}{l}\text { France, Germany, } \\
\text { Italy, Spain and UK }\end{array}$ & No convergence \\
\hline $\begin{array}{l}\text { Zambrano-Monserrate et al., } \\
2020[18]\end{array}$ & EFP and Biocapacity & $\begin{array}{l}\text { Dynamic spatial } \\
\text { Durbin model }\end{array}$ & 158 countries & Spatial effects \\
\hline
\end{tabular}

NOTE: Two-regime threshold Autoregressive (TAR); Convergence (C.); Ecological Footprint per capita (EFP pc); Geographically Weighted Regression model (GWR); Ordinary Least Square Regression (OLS); Association of Southeast Asian Nations (ASEAN-5); Local Spatial Association Index (LISA); Successive Overrelaxation Method (SOR); Grey Model First Order One Variable (Grey GM $(1,1)$ ): Augmented Mean Group (AMG); Colombia, Indonesia, Vietnam, Egypt, Turkey and South Africa (CIVETS). 
Other papers have focused on the Convergence Club analysis. In this case, economies are grouped by common characteristics and each group has the same steady-state equilibrium, and each group reaches its own equilibrium. Solarin et al. (2019) [13] demonstrated 10 convergence clubs with regards to the EFP in their analysis of 92 countries. Ulucak and Apergis (2018) [3] employed the club-clustering-convergence method to examine the convergence in EU countries and document the presence of certain convergence clubs. while Erdogan and Okumus (2021) [4] provided a similar analysis for different income groups of countries using a panel-stationarity test and obtained several convergence clubs. Ulukak et al. (2020) [14] examined the convergence of 23 Sub-Saharan Africa countries using log t regression and found several clubs of convergence.

Contrary to these studies, the following research studies reached the opposite conclusion, namely that EFPs do not converge: Haider et al. (2012) [15] for 172 countries using the Phillips-Sul approach and Caglar et al. (2021) [16] for France, Germany, Italy, Spain and the U.K. employing the SOR unit root test.

There is a smaller number of papers that deal with other topics. These are the cases of Wu and Liu (2020) [17] and Zambrano-Monserrate et al. (2020) [18] that explored spatial distribution and the spatial effects of economic variables on the EFP. Other papers estimated relations of EFP with other economic variables (Nathaniel et al., 2020) [19] and offered evidence of the main driving forces of EFP evolution in China's provinces $(\mathrm{Wu}, 2020)$ [20]. We can also find papers that offer forecasts (Guo et al., 2020) [21]. However, no studies were found that analyze the short-run dynamics of EFP and offer evidence of the cross-country links to this environmental variable.

\section{Data and Methods}

\subsection{Data}

Annual data on the EFP per capita (global hectares per capita) for the EU countries were obtained from the Global Footprint Network (http:/ / data.footprintnetwork.org, accessed on 10 November 2021), spanning the period 1962-2017. The time period was consistent with data availability for Austria, Belgium, Sweden, France, Netherlands, Poland, Greece, Finland, Denmark, Italy, Ireland, Germany, United Kingdom, Luxembourg, Cyprus, Malta, Spain, Portugal, Hungary, Bulgaria and Romania. The annual series on EFP were log-transformed and differentiated $(\Delta=1-L$, being $L$ the lag operator) in order to obtain the EFP short-run behavior of the European countries. The analysis focuses on the EU countries since the EU has adopted some of the highest environmental standards on a global basis, as well as common environmental policies.

\subsection{Model}

Our proposal to offer information about the dynamics of the EFP begins by applying dynamic factor analysis to estimate a short-run index of the EFP for the EU. The dynamic factor model is based on the assumption that a small number of unobserved latent factors, $f_{t}$, generate the observed time series through a stochastically perturbed linear structure. Formally, in the model it is assumed that the pattern of observed co-movements of a highdimensional vector of time-series countries, $X_{t}=\Delta \ln E F P_{i . t}$, (where EFP is the growth rates of global hectares per capita by country) can be represented by a few unobserved, latent common dynamic factors. The latent factors follow the time series process and are commonly taken to be a vector autoregression (VAR). In equations, the dynamic factor model is

$$
\begin{gathered}
X_{t}=\Lambda f_{t}+e_{t} \\
f_{t}=\psi(L) f_{t-1}+\eta_{t}
\end{gathered}
$$

where there are $N$ countries, so $X_{t}$ and $e_{t}$ are $N \times 1$, there are $m$ dynamic factors so $f_{t}$ and $\eta_{t}$ are $m \times 1, \Lambda=\left(\lambda_{1}, \lambda_{2}, \ldots, \lambda_{m}\right)$ is $N \times m, L$ is the lag operator, and the lag polynomial matrix $\psi(L)$ is $m \times m$. The $i$-th $\lambda_{i}$ are called factor loadings for the $i$-th countries, $X_{i t}$. The idiosyncratic disturbances, $e_{t}=\left(e_{1, t}, e_{2, t}, \ldots, e_{N, t}\right)^{\prime}$, are the specific elements of each series contained in a vector; they are serially correlated and slightly cross-sectionally correlated 
with other variables in the model and are mutually uncorrelated at all leads and lags, that is, $E e_{i t} e_{j s}=0$ for all $\mathrm{s}$ if $i \neq s$. They are assumed to be uncorrelated with the factor innovations at all leads and lags, that is, $E e_{t} \eta_{t-k}^{\prime}=0$ for all $k$. The $p t h$ order autoregressive polynomial, $\psi_{i}(L)$, is assumed to have stationary roots. As we did here, it is common to reduce the number of parameters by estimating the signal-to-noise ratios $q_{i, m}=\frac{\sigma_{\eta, i}^{2}}{\sigma_{e, i}^{2}}$ (see Harvey and Trimbur, 2008 [22], for its importance for spectral analysis).

Assuming that all the processes in (1) are stationary and not cointegrated, we used the GROCER's Econometric Toolbox written by Dubois and Michaux, 2019 [23], which provides the standard estimation method by maximizing the likelihood of the corresponding model and estimation accuracy via the Kalman filter, after a suitable reparameterization of the model in a state-space form. This method allowed us to explicitly model the dynamic of the factors $f_{i, t}$ that can take an autoregressive-moving-average $\operatorname{ARMA}(\mathrm{p}, \mathrm{q})$ form as:

$$
\left(1+\phi_{1} L+\ldots+\phi_{p} L^{p}\right) f_{i, t}=\left(1+\theta_{1} L+\ldots+\theta_{q} L^{q}\right) \eta_{t}
$$

expressed in matrix form (1) and of the residuals $e_{i, t}$ than can take an autoregressive AR form as:

$$
\left(1+\delta_{1,1} L+\ldots+\delta_{1, l_{i}} L^{i}\right) e_{i, t}=\xi_{i, t}
$$

where $l_{i}$ is the order of the idiosyncratic AR governing $e_{i, t}$.

In our proposal, we first confirmed the existence of only one common factor, $\hat{f}_{1, t}, \mathrm{em}$ ploying the statistical criterion proposed by Bai and Ng, 2002 [24]. This single common factor represents the short-run index for the EFP of the EU. Furthermore, for an appropriate interpretation of results, we standardized the loading factors: $\lambda_{i} \frac{\sigma_{\hat{f}_{1}}}{\sigma_{x_{i}}}=\frac{\operatorname{cov}\left(x_{i}, f_{1}\right)}{\sigma_{f_{1}}^{2}} \frac{\sigma_{\hat{f}}}{\sigma_{x_{i}}}=\frac{\operatorname{cov}\left(x_{i}, f_{1}\right)}{\sigma_{x_{i}} \sigma_{f_{1}}}=\rho_{i}$, such that it provided an estimation of the correlation or linkages between the countries' EFPs with the common factor. The values that were parametrically obtained, $\rho_{i}$, are the proportion of the total variation explained by the common factor, which offers a measure of the degree to which the country is co-moving following the short-run dynamic pattern of EFP in Europe (the short-run index of EFP) over the period.

To analyze the possible results obtained by $\rho_{i}$, we differentiated three types of results according to the percentage of variation explained by the short-run index of EFP:

- Group 1: $\rho_{i} \geq 0.5$-Denoting a strongly linked EFP. We interpret that this result is obtained by countries that share the short-run dynamics of EFP in Europe and we could expect them to exert influence on the neighboring countries.

- Group 2: $0<\rho_{i}<0.5$-Denoting emissions with weak links. In this case, countries are not so influenced by the short-run dynamics of the EFP common pattern.

- Group 3: $\rho_{i}=0$-Denoting an independent EFP pattern. This type of result implies that these countries are not linked with the European pattern of EFP.

\section{Results}

The results of the estimation according to the dynamic factor model in (1) are shown in Figure 1 and Table A1 in the Appendix A. The AR idiosyncratic parameter and noise ratio confirm the suitability and dynamicity of the model. The significance of the loading factors indicates which countries are sharing a short-run dynamic behavior and which are not. Results confirm that all of the factor loadings are significant and statistically similar, with the exceptions of Luxembourg, the Netherlands, Portugal, Spain and Sweden. These countries were then excluded from the estimation of the model, which is why they do not appear in Figure 1. Luxembourg, the Netherlands, Portugal, Spain and Sweden follow independent short-run behavior in their EFP and thus, they are considered to be independent from the European EFP dynamic. 


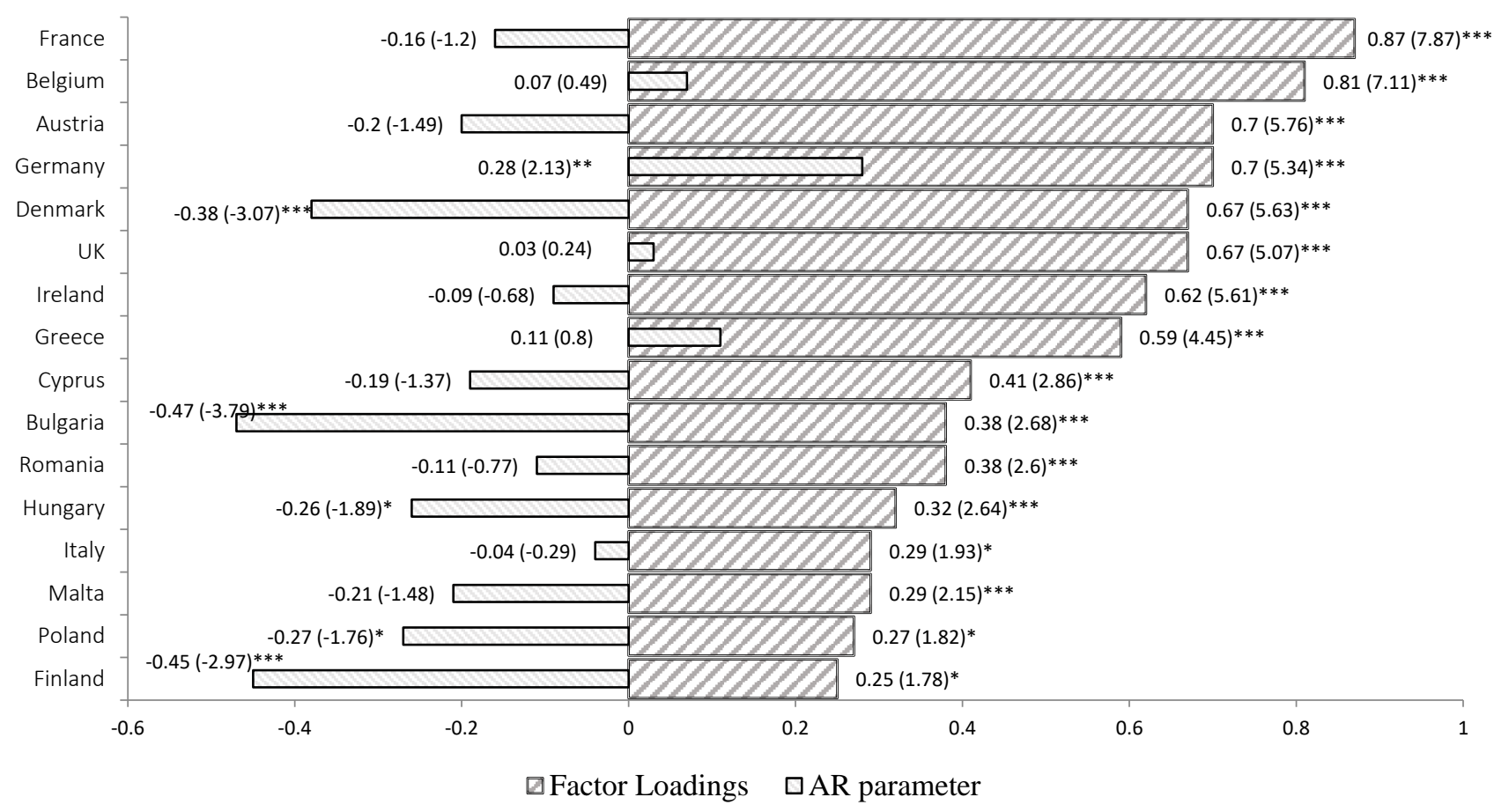

Figure 1. Countries ordered by factor loadings in model (1) and AR idiosyncratic parameters in (3). Period 1962-2017. Note: AR: Autoregressive. In () t-statistics at $* 90 \%, * * 95 \%$ and $* * * 99 \%$ of significance. No significant countries in factor model: Luxembourg, the Netherlands, Portugal, Spain and Sweden.

Additionally, the proportion of total variation explained by the factor loading can be a measure of the degree of the cross-country links. Following the criteria established in the methodology section, we can identify countries that strongly share the common short-term dynamic pattern of the EU $\left(\rho_{i} \geq 0.5\right)$. In Figure 1 the European countries are ordered by the value of their factor loadings from highest to lowest in order to facilitate analysis. We can observe that the main members of the EU, i.e., France, Germany, the UK, Austria, Belgium and Denmark, obtained values of $\rho_{i} \geq 0.5$. This group is joined by Ireland and Greece, which, although with lower values, also achieve the results of $\rho_{i} \geq 0.5$.

In our analysis, we also find the countries for which the emissions show weak linkages $\left(0<\rho_{i}<0.5\right)$. This is the case of Cyprus, Bulgaria, Rumania, Hungary, Italy, Malta, Poland and Finland. The cases of Italy and Finland may be surprising, but their results may be related to the fact that they are closer to maintaining independent positions than to sharing the short-term behavior of the EU. For the rest of the countries, the enlargements to include the new member states in Central and Eastern Europe have given a greater dimension to the EU, but their progress towards a common EFP dynamic is in less-advanced stages. But the fact that they maintain significant correlations with the common factor is evidence of the positive progress of their environmental behavior.

Based on the previous results, we also provide a map in order to more intuitively follow the three groups of countries that were obtained (see Figure 2). The darker the shading of the map areas, the stronger the links across the EFP. It is straightforward to perceive that the core European countries are the ones that show more influence on the European EFP dynamic.

The information on the dynamics of the European EFP also allows for the analysis of their cyclical properties. Figure 3 shows the dynamic of the European EFP throughout the time period beginning in 1962 and ending in 2017. The characteristics of the changes in the short-run index of the EFP over the period show quite a symmetrical behavior, with the same average duration from peak to peak than from trough to trough. Although, we find that the averages of the duration (2.86 years) and amplitude ( 8.5 years) of the reduction in footprint are greater than the average duration (2.57 years) and average 
amplitude (6 years) of the expansions. Another result of interest is that the period of best EFP performance occurs during the period 1998-2008, during which period there was a decrease in environmental degradation.

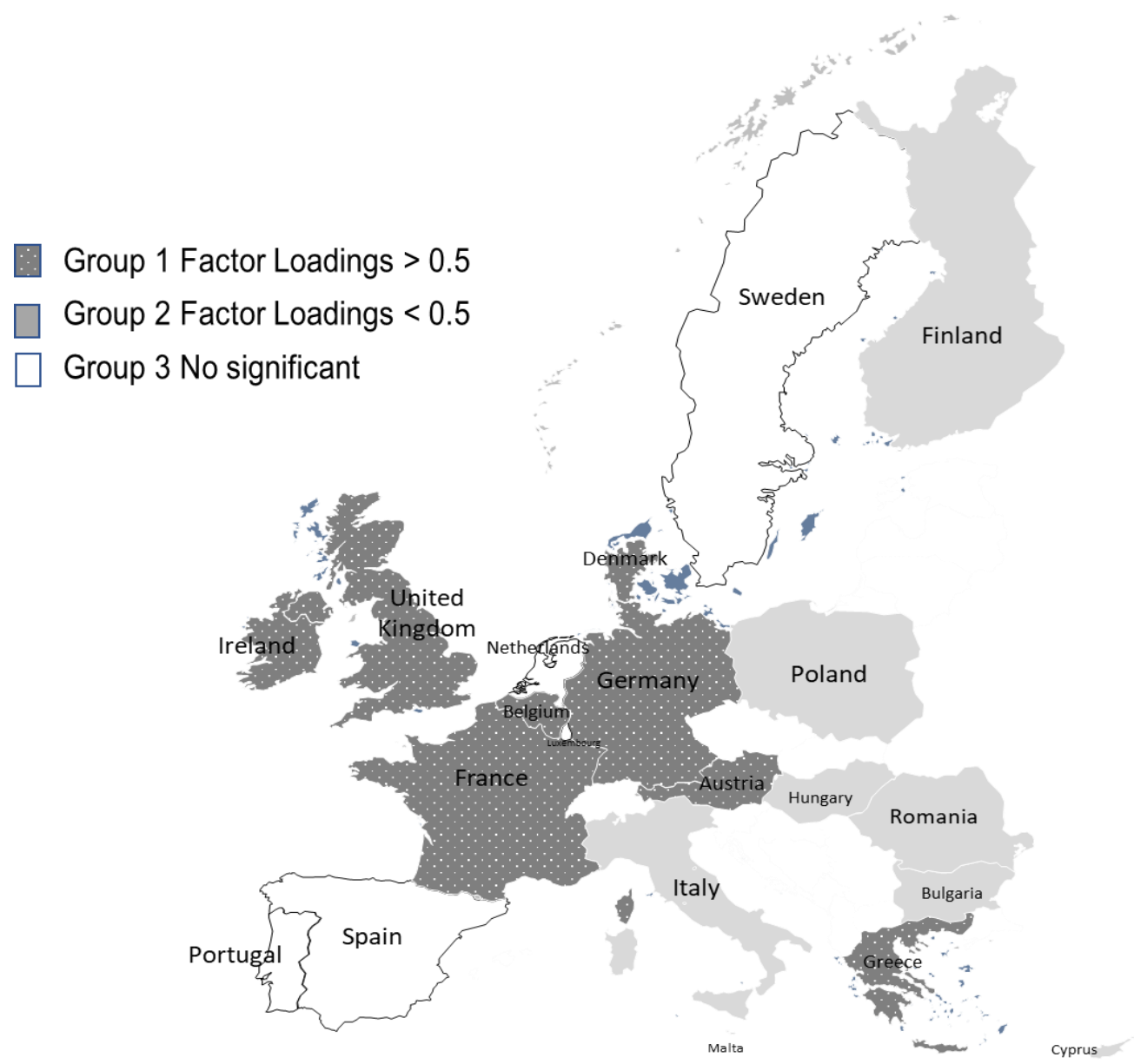

Figure 2. Spatial distribution of the European country's correlation.

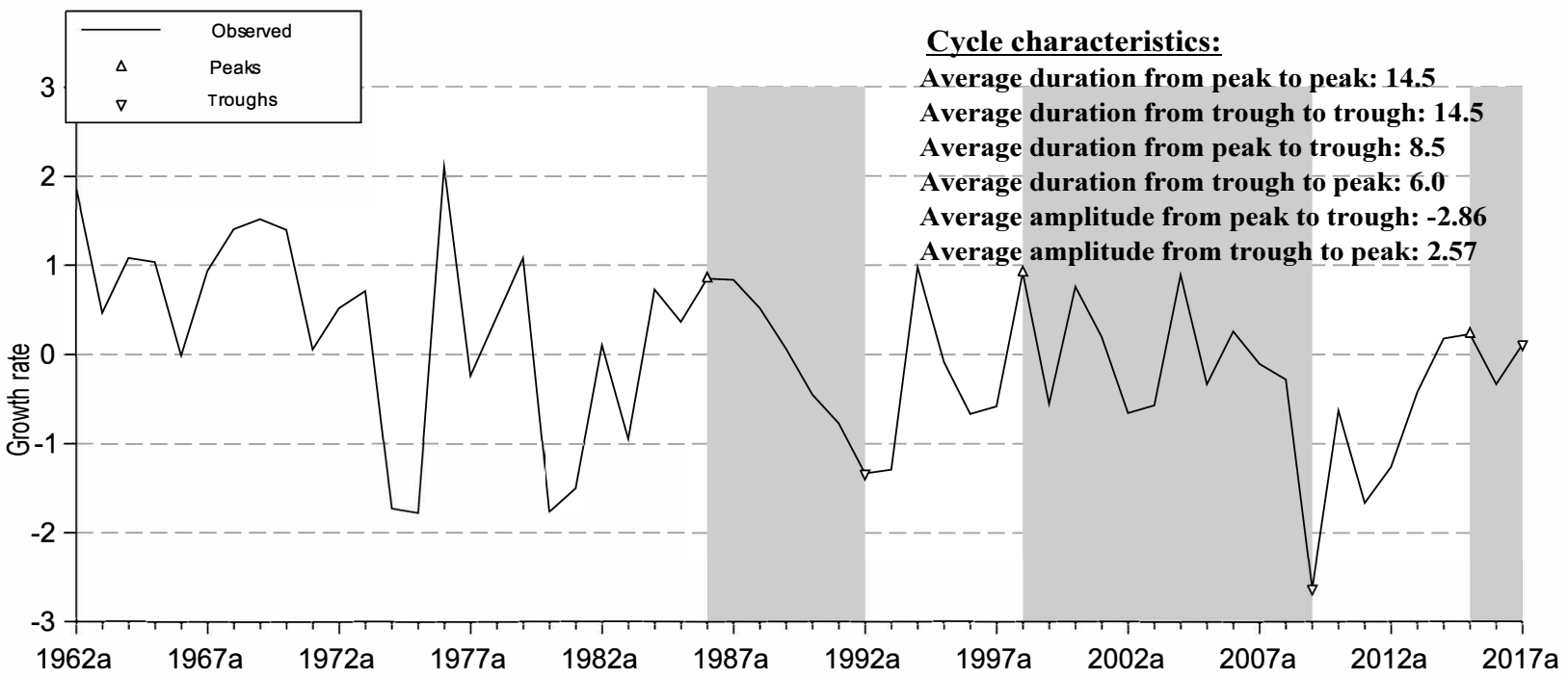

Figure 3. Dating the EFP Index and cycle characteristics. Note: Shaded areas correspond to the declining phases in the EU EFP. Source: own compilation using Harding and Pagan (2002) [25]. 


\section{Robustness Checks}

We performed a number of robustness checks in order to test the validity of our results. First, we confirmed the existence of only one common factor, $\hat{f}_{E F P, t}$, by employing the statistical criterion proposed by Bai and $\mathrm{Ng}$ (2002) [24]. The number of dynamic factors, $p$, according to these authors, is where $p \leq r$ is the number of static factors determined by Bai and $\mathrm{Ng}$ (2007) [26], and where $p=1$ since $r=1$ according to the following criteria:

$$
\begin{gathered}
I C_{p 1}(q)=\log \left(\operatorname{det}\left(\sum\right)\right)+q \frac{(N+T)}{n T}+\log \left(\frac{n T}{N+T}\right) \\
I C_{p 2}(q)=\log \left(\operatorname{det}\left(\sum\right)\right)+q \frac{(N+T)}{n T}+\log (\min (n, T)) \\
I C_{p 3}(q)=\log \left(\operatorname{det}\left(\sum\right)\right)+q \frac{\log (\min (n, T))}{(\min (n, T))}
\end{gathered}
$$

where $\sum=$ variance matrix of residual $e_{t}$.

Next, we confirmed the robustness of our results by testing the stability of the estimated parameters in model (1) to check the existence of structural or temporal breaks that reflect changes in European behaviors that are related to the difficulties of maintain the EFP short-run behavior. Following Bueno et al. (2011) [27], if the date of a possible break is unknown, then a recursive testing procedure can be employed. The null hypothesis $H_{0}$ of the parameters' stability of each model is $H_{0}: \rho_{i}(\tau)=0$. Recursive estimations $\hat{\rho}_{i}(\tau)$ are obtained from:

$$
x_{i, t}=\rho_{i}(\tau) \hat{f}_{E F P, t}+v_{i, t}(\tau)
$$

and the F-type statistic (Wald-type statistic) to test for a break of an unknown date is

$$
F_{\text {SupWald }, i}=\max \left[F_{i}\left(\tau_{0}\right), F_{i}\left(\tau_{0}+1\right), \ldots, F_{i}(T-1), F_{i}(T)\right]
$$

where each of the $F(\tau)$ is defined as:

$$
F(\tau)=\frac{1}{q}\left[R \rho_{j}(\tau)-\rho_{j}\right]^{\prime}\left(R \hat{\sum}(\tau) R^{\prime}\right)^{-1}\left[R \rho_{j}(\tau)-\rho_{j}\right]
$$

$\hat{\Sigma}(\tau)$ must be robust to heteroskedasticity and autocorrelation. For example, by employing the Newey-West (1987) [28] estimator.

The asymptotic distribution of the $F_{S u p W a l d, i}$ statistic is not standard because the break date appears only under the alternative hypothesis. In this work, empirical critical values with no asymptotic sample sizes and autocorrelated errors were calculated by the Monte Carlo simulation according to our data characteristics, that is, by assuming autocorrelation disturbances in (1) and (5) and for the available sample sizes. For more details see Bueno et al. (2011) [27].

We show the results of the estimation of the breaks and the $F_{\text {SupWald }, i}$ (Wald type statistic) in Table 2 and Figure 4. Some temporal breaks were found in Romania and Hungary in 1989 which can be linked to the economic crisis in these countries.

Table 2. Estimation breaks of model (1) for EU countries, 1962-2017.

\begin{tabular}{cccccccc}
\hline Countries & Trimming & $\mathbf{9 0} \%$ & $\mathbf{9 5 \%}$ & $\mathbf{9 9 \%}$ & $\boldsymbol{F}_{\text {SupWald, } \boldsymbol{i}}$ & Break Date & Breaks \\
\hline France & $20 \%$ & 5.6 & 7.9 & 16.2 & 0.9 & 1972 & \\
Belgium & $20 \%$ & 4.9 & 7 & 15.8 & 3.3 & 1985 & \\
Austria & $20 \%$ & 5.2 & 7 & 12.5 & 1 & 1972 & \\
Germany & $20 \%$ & 5.2 & 6.9 & 10.6 & 1.2 & 1974 & \\
Denmark & $20 \%$ & 4.9 & 7.2 & 14 & 1.7 & 1992 & \\
UK & $30 \%$ & 3.5 & 4.9 & 10.1 & 1.3 & 1989 & \\
Ireland & $30 \%$ & 3.3 & 4.7 & 8.8 & 0.4 & 1978 & \\
Greece & $20 \%$ & 5.1 & 7 & 12.8 & 1 & 1996 & \\
\hline
\end{tabular}


Table 2. Cont.

\begin{tabular}{cccccccc}
\hline Countries & Trimming & $\mathbf{9 0} \%$ & $\mathbf{9 5} \%$ & $\mathbf{9 9} \%$ & $\boldsymbol{F}_{\text {SupWald, } \boldsymbol{i}}$ & Break Date & Breaks \\
\hline Cyprus & $20 \%$ & 5.7 & 7.7 & 13.5 & 1 & 1979 & \\
Bulgaria & $20 \%$ & 4.9 & 6.7 & 15.7 & 2.1 & 1988 & \\
Romania & $20 \%$ & 5.2 & 7.9 & 14.8 & 5.6 & $1989 *$ & Temporal break \\
Hungary & $20 \%$ & 5.1 & 7.3 & 15.9 & 8.8 & $1989 * *$ & Temporal break \\
Italy & $20 \%$ & 5 & 7.3 & 15.2 & 0.6 & 1972 & \\
Malta & $20 \%$ & 5.2 & 7.4 & 17.1 & 0.7 & 1978 & \\
Poland & $20 \%$ & 5.1 & 6.9 & 10.6 & 0.8 & 1980 & \\
Finland & $20 \%$ & 2.2 & 3.4 & 5.5 & 3.2 & 1980 & \\
\hline
\end{tabular}
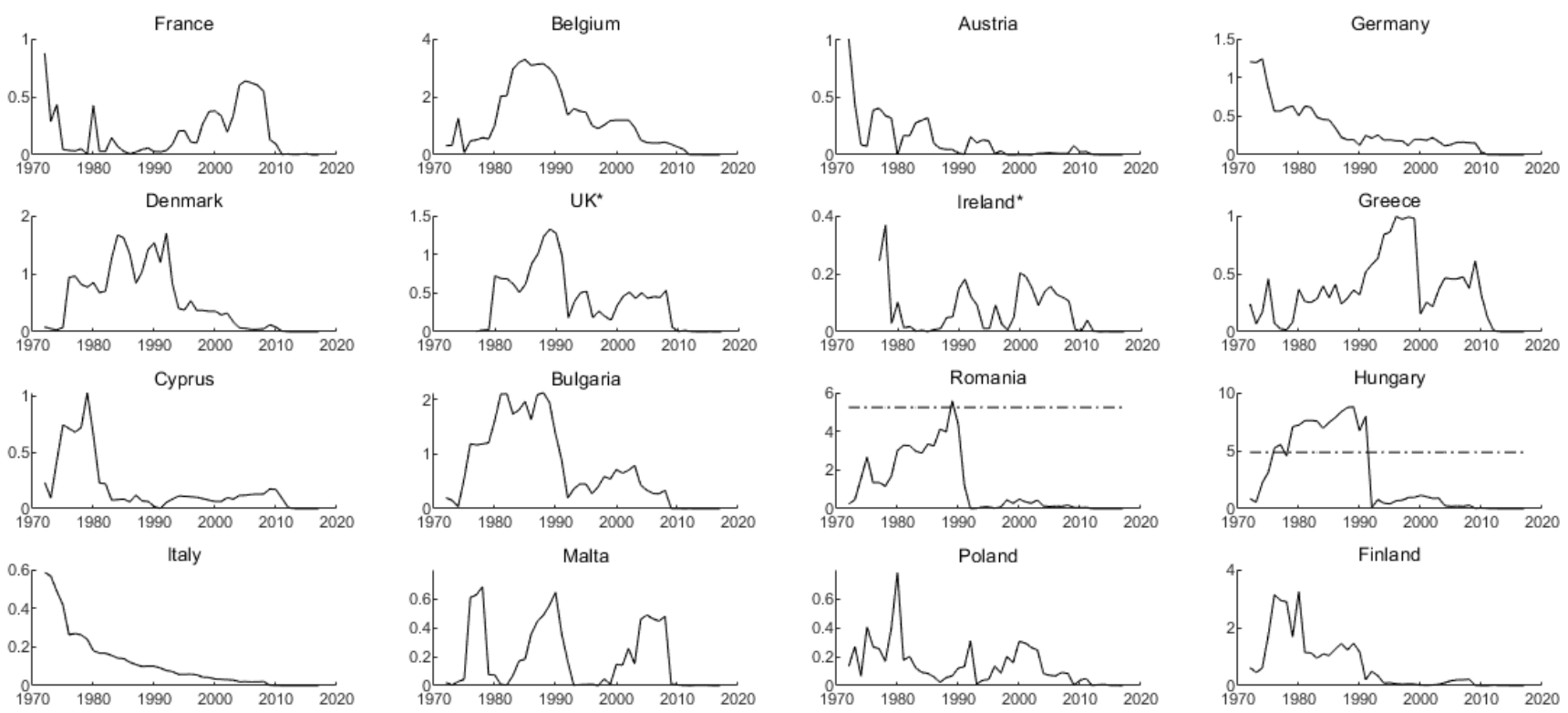

Figure 4. The asymptotic distribution of the $\boldsymbol{F}_{\text {SupWald }, i}$ statistics of model (1) at $20 \%$ of trimming. Note: $y$-axis: value of $F_{\text {SupWald }, i}{ }^{*}$ at $30 \%$ of trimming. Source: Own compilation using Matlab.

\section{Conclusions}

The EFP is an appealing environmental factor that shows the human impact on the environment and is widely used for sustainability assessments. Most of the work on the EFP has been dedicated to determining the existence of convergence and has focused only on the long-run side of the analysis. In this paper, we broadened the possibilities of its investigation by measuring a short-run index of the EFP for the EU and testing the existence of cross-country links. To this end, we used a dynamic factor model which enabled estimation of the dynamics of the EFP in the EU and used the information about the proportion of variation explained by this index to characterize countries according to their cross-country links over the extended period of 1962-2017. So far, this type of analysis has not received enough attention in the literature.

The information on the dynamics of the EFP in Europe shows that the period of best EFP performance occurs over the period 1998-2008 during the crisis there, due to an increase in environmental degradation. Our results for the EU demonstrate the existence of three groups of countries according to the degree to which they share the EU short-run dynamics of EFP. The empirical findings reveal the existence of strong cross-country links across some of the main European countries: France, Austria, Belgium, Germany, Denmark and the U.K. These links allow us to extract information on the indirect effects that the dynamics of the EFP can have on their neighboring countries. We also find countries with weak links and countries with EFP-independent patterns. From the policy point of view, our findings recommend that policies related to the environment consider the distinctive 
short-run path of the EFP in Europe. The existence of different patterns of short-run EFP behavior shows that mitigation policies are required, and that the environmental degradation will not ease without exogenous intervention. For this, knowing the pattern of the EFP is crucial for evaluating the success of environmental actions.

This empirical study extends the literature on the EFP by serving as the first paper to investigate short-run characteristics of the EFP across European countries. Understanding short-run characteristics helps in assessing whether European sustainability policies can be effective and should therefore be reinforced. The methodology proposed in this article is a starting point for future work related to the understanding of the dynamics of the EFP. Its application will allow policies to be modulated for each country. Further research on how to contribute to the understanding of these cross-country links is needed in the environmental degradation literature.

Author Contributions: Conceptualization, M.J.D.-R.; Data curation, A.C.-A.; Formal analysis, S.d.L.-S.; Methodology, M.J.D.-R.; Resources, S.d.L.-S. and A.C.-A.; Writing-original draft, M.J.D.-R., M.J.D.-R. and A.C.-A. All the authors have equally contributed to the final version of this paper. All authors have read and agreed to the published version of the manuscript.

Funding: This research received no external funding.

Conflicts of Interest: The authors declare no conflict of interest.

\section{Appendix A}

Table A1. Estimation breaks of model (1) for EU countries, 1962-2017.

\begin{tabular}{cccc}
\hline Countries & Factor Loadings & $\begin{array}{c}\text { AR Idiosyncratic } \\
\text { Parameters }\end{array}$ & Residual Variance \\
\hline France & $0.87(7.87)^{* * *}$ & $-0.45(-2.97)^{* * *}$ & $0.26(3.77)^{* * *}$ \\
Belgium & $0.81(7.11)^{* * *}$ & $-0.27(-1.76)^{* *}$ & $0.34(4.35)$ \\
Austria & $0.7(5.76)^{* * *}$ & $-0.21(-1.48)$ & $0.51(4.82)$ \\
Germany & $0.7(5.34)^{* * *}$ & $-0.04(-0.29)$ & $0.57(4.86)$ \\
Denmark & $0.67(5.63)^{* * *}$ & $-0.26(-1.89)^{*}$ & $0.51(4.87)$ \\
UK & $0.67(5.07)^{* * *}$ & $-0.11(-0.77)$ & $0.62(4.94)$ \\
Ireland & $0.62(5.61)^{* * *}$ & $-0.47(-3.79)^{* * *}$ & $0.51(4.91)$ \\
Greece & $0.59(4.45)^{* * *}$ & $-0.19(-1.37)$ & $0.7(5.06)$ \\
Cyprus & $0.41(2.86)^{* * *}$ & $0.11(0.8)$ & $0.83(5.18)$ \\
Bulgaria & $0.38(2.68)^{* * *}$ & $-0.09(-0.68)$ & $0.87(5.21)$ \\
Romania & $0.38(2.6)^{* * *}$ & $0.03(0.24)$ & $0.87(5.21)$ \\
Hungary & $0.32(2.64)^{* * *}$ & $-0.38(-3.07) * * *$ & $0.77(5.23)$ \\
Italy & $0.29(1.93)^{*}$ & $0.28(2.13) * *$ & $0.91(5.23)$ \\
Malta & $0.29(2.15)^{* *}$ & $-0.2(-1.49)$ & $0.89(5.25)$ \\
Poland & $0.27(1.82)^{*}$ & $0.07(0.49)$ & $0.93(5.25)$ \\
Finland & $0.25(1.78)^{*}$ & $-0.16(-1.2)$ & $0.92(5.26)$ \\
\hline
\end{tabular}

Note: AR: Autoregressive; In () t-statistics at ${ }^{*} 90 \%,{ }^{* *} 95 \%$ and ${ }^{* * *} 99 \%$ of significance. Note: Luxembourg, Netherlands, Portugal, Spain and Sweden are not significance.

\section{Notes}

1. Dynamic panel Model offers an alternative measure for cross-country links to the obtained through conventional input-output models or other types of analysis. In this case, the econometric model employed measure parametrically an indicator that captures the dynamics of EFP from the growth rates of global hectares per capita by country.

2. Croatia, Estonia, Latvia, Lithuania, Slovakia, Slovenia and Czech Republic are omitted from our analysis due to the lack of availability data for the same sample period.

3. This methodology is frequently used for business cycle estimations but the interest in the analysis of the cycle has led to the use of its tools in environmental studies. These are the case of McKitrick and Wood, 2013[29], Doda, 2014[30], Delgado et al., 2018[31], De Lucas et al, 2021[32] and Cabezas et al., 2020[33]. These pa-pers demonstrate the interest and suitability of the Dynamic Factor Model to understand the short-run behavior of environmental variables. 


\section{References}

1. Recep, U.; Lin, D. Persistence of Policy Shocks to Ecological Footprint of the USA. Ecol. Indic. 2017, 80, 337-343. [CrossRef]

2. Global Footprint Network. Ecological Footprint. 2021. Available online: http://data.footprintnetwork.org/ (accessed on 10 November 2021).

3. Ulucak, R.; Apergis, N. Does convergence really matter for the environment? An application based on club convergence and on the ecological footprint concept for the EU countries. Environ. Sci. Policy 2018, 80, 21-27. [CrossRef]

4. Erdogan, S.; Okumus, I. Stochastic and club convergence of ecological footprint: An empirical analysis for different income group of countries. Ecol. Indic. 2020, 121, 107-123. [CrossRef]

5. Al-Mulali, U.; Weng-Wai, C.; Sheau-Ting, L.; Mohammed, A.H. Investigating the environmental Kuznets curve (EKC) hypothesis by utilizing the ecological footprint as an indicator of environmental degradation. Ecol. Indic. 2015, 48, 315-323. [CrossRef]

6. Solarin, S.A. Convergence in $\mathrm{CO}_{2}$ emissions, carbon footprint and ecological footprint: Evidence from OECD countries. Environ. Sci. Pollut. Res. 2019, 26, 6167-6181. [CrossRef] [PubMed]

7. Stern, D.I.; The Environmental Kuznets Curve: A Primer. CCEP Working Paper 1404. 2014. Available online: https://ccep. crawford.anu.edu.au/ (accessed on 1 October 2021).

8. Bello, M.O.; Solarin, S.A.; Yen, Y.Y. The impact of electricity consumption on $\mathrm{CO}_{2}$ emission, carbon footprint, water footprint and ecological footprint: The role of hydropower in an emerging economy. J. Environ. Manag. 2018, 219, 218-230. [CrossRef]

9. Solarin, S.A.; Al-Mulali, U. Influence of foreign direct investment on indicators of environmental degradation. Environ. Sci. Pollut. Res. 2018, 25, 24845-24859. [CrossRef]

10. Bilgili, F.; Ulucak, R. Is there deterministic, stochastic, and/or club convergence in ecological footprint indicator among G20 countries? Environ. Sci. Pollut. Res. 2018, 25, 35404-35419. [CrossRef]

11. Yilanci, V.; Pata, U.K. Convergence of per capita ecological footprint among the ASEAN-5 countries: Evidence from a non-linear panel unit root test. Ecol. Indic. 2020, 113, 106178. [CrossRef]

12. Sarkodie, S.A. Environmental performance, biocapacity, carbon \& ecological footprint of nations: Drivers, trends and mitigation options. Sci. Total. Environ. 2020, 751, 141912. [CrossRef] [PubMed]

13. Solarin, S.A.; Tiwari, A.K.; Bello, M.O. A multi-country convergence analysis of ecological footprint and its components. Sustain. Cities Soc. 2019, 46, 101422. [CrossRef]

14. Ulucak, R.; Kassouri, Y.; Ilkay, S.; Altıntaş, H.; Garang, A.P.M. Does convergence contribute to reshaping sustainable development policies? Insights from Sub-Saharan Africa. Ecol. Indic. 2020, 112, 106140. [CrossRef]

15. Haider, S.; Akram, V.; Ali, J. Does biomass material footprint converge? Evidence from club convergence analysis. Environ. Sci. Pollut. Res. 2021, 28, 27362-27375. [CrossRef] [PubMed]

16. Caglar, A.E.; Balsalobre-Lorente, D.; Akin, C.S. Analysing the ecological footprint in EU-5 countries under a scenario of carbon neutrality: Evidence from newly developed sharp and smooth structural breaks in unit root testing. J. Environ. Manag. 2021, 295, 113155. [CrossRef] [PubMed]

17. Wu, D.; Liu, J. Spatial and Temporal Evaluation of Ecological Footprint Intensity of Jiangsu Province at the County-Level Scale. Int. J. Environ. Res. Public Health 2020, 17, 7833. [CrossRef]

18. Zambrano-Monserrate, M.A.; Ruano, M.A.; Ormeño-Candelario, V.; Sanchez-Loor, D. Global ecological footprint and spatial dependence between countries. J. Environ. Manag. 2020, 272, 111069. [CrossRef] [PubMed]

19. Nathaniel, S.; Nwodo, O.; Sharma, G.; Shah, M. Renewable energy, urbanization, and ecological footprint linkage in CIVETS. Environ. Sci. Pollut. Res. 2020, 27, 19616-19629. [CrossRef] [PubMed]

20. Wu, D. Spatially and temporally varying relationships between ecological footprint and influencing factors in China's provinces Using Geographically Weighted Regression (GWR). J. Clean. Prod. 2020, 261, 121089. [CrossRef]

21. Guo, J.; Ren, J.; Huang, X.; He, G.; Shi, Y.; Zhou, H. The Dynamic Evolution of the Ecological Footprint and Ecological Capacity of Qinghai Province. Sustainability 2020, 12, 3065. [CrossRef]

22. Harvey, A.; Trimbur, T. Trend Estimation and the Hodrick-Prescott Filter. J. Jpn. Stat. Soc. 2008, 38, 41-49. [CrossRef]

23. Dubois, É.; Michaux, E. Grocer 1.72: An econometric toolbox for Scilab 2019. 2019. Available online: http:// dubois.ensae.net/ grocer.html (accessed on 12 October 2021).

24. Bai, J.; Ng, S. Determining the Number of Factors in Approximate Factor Models. Econometrica 2002, 70, 191-221. [CrossRef]

25. Harding, D.; Pagan, A. Dissecting the cycle: A methodological investigation. J. Monetary Econ. 2002, 49, 365-381. [CrossRef]

26. Bai, J.; Ng, S. Determining the Number of Primitive Shocks in Factor Models. J. Bus. Econ. Stat. 2007, 25, 52-60. [CrossRef]

27. Bueno, J.L.C.; Santos, S.D.L.; Rodríguez, M.J.D.; Ayuso, I. Testing for structural breaks in factor loadings: An application to international business cycle. Econ. Model. 2011, 28, 259-263. [CrossRef]

28. Newey, W.K.; West, K.D. A Simple, Positive Semi-Definite, Heteroskedasticity and Autocorrelation Consistent Covariance Matrix. Econometrica 1987, 55, 703. [CrossRef]

29. McKitrick, R.; Wood, J. Co-fluctuation patterns of per capita carbon dioxide emissions: The role of energy markets. Energy Econ. 2013, 39, 1-12. [CrossRef]

30. Doda, B. Evidence on business cycles and emissions. J. Macroecon. 2014, 40, 214-227. [CrossRef]

31. Delgado-Rodríguez, M.J.; Ares, A.C.; Santos, S.D.L. Cyclical fluctuation patterns and decoupling: Towards common EU-28 environmental performance. J. Clean. Prod. 2018, 175, 696-706. [CrossRef] 
32. De Lucas-Santos, S.; Delgado-Rodríguez, M.J.; Cabezas-Ares, A. Cyclical convergence in per capita carbon dioxide emission in US states: A dynamic unobserved component approach. Energy 2020, 217, 119349. [CrossRef]

33. Cabezas-Ares, A.; Delgado-Rodríguez, M.; Lucas-Santos, S. The Dynamics of Cyclical Convergence and Decoupling in the Environmental Performance of Spanish Regions. Sustainability 2020, 12, 8569. [CrossRef] 